\title{
Quantitative Determination of Apoptosis of Pancreatic $\beta$-Cells in a Murine Model of Type 1 Diabetes Mellitus
}

\author{
Ayahisa Watanabe ${ }^{1,2}$, Ken-ichi Nishijima ${ }^{3}$, Songji Zhao ${ }^{3,4}$, Yan Zhao ${ }^{3}$, Yoshikazu Tanaka ${ }^{2}$, Hiroshi Takemoto ${ }^{2}$, \\ H. William Strauss ${ }^{5}$, Francis G. Blankenberg ${ }^{6}$, Nagara Tamaki $^{4}$, and Yuji Kuge ${ }^{1,7}$ \\ ${ }^{1}$ Department of Radiobiology, Graduate School of Medicine, Hokkaido University, Sapporo, Japan; ${ }^{2}$ Shionogi Innovation Center for \\ Drug Discovery, Shionogi and Co., Ltd., Sapporo, Japan; ${ }^{3}$ Department of Tracer Kinetics and Bioanalysis, Graduate School of \\ Medicine, Hokkaido University, Sapporo, Japan; ${ }^{4}$ Department of Nuclear Medicine, Graduate School of Medicine, Hokkaido \\ University, Sapporo, Japan; ${ }^{5}$ Department of Nuclear Medicine, Memorial Sloan-Kettering Cancer Center, New York, New York; \\ ${ }^{6}$ Department of Pediatric Radiology, Stanford University School of Medicine, Palo Alto, California; and ${ }^{7}$ Central Institute of Isotope \\ Science, Hokkaido University, Sapporo, Japan
}

Type 1 diabetes mellitus is characterized by a significant deficit in pancreatic $\beta$-cell mass, presumably caused by $\beta$-cell apoptosis. We investigated the incidence of $\beta$-cell apoptosis in streptozotocin-treated mice and nonobese diabetic (NOD) mice with ${ }^{99 m}$ Tc-annexin A5. Methods: Vehicle-treated mice, streptozotocin-treated mice, and NOD mice at the ages of $5,9,16$, and 20 wk (5-8 mice per group) were injected with $99 \mathrm{mTc}$ annexin A5 and sacrificed $6 \mathrm{~h}$ later for autoradiography, and the regional ${ }^{99 \mathrm{~m} T c-a n n e x i n} \mathrm{~A} 5$ level in the pancreas was evaluated. Pancreatic islets were identified by insulin immunohistochemical staining, and apoptotic cells were determined by terminal deoxynucleotidyl transferase-mediated dUTP nickend labeling (TUNEL) staining. The $99 \mathrm{mTC}$-annexin A5 level in pancreatic islets was expressed as the percentage injected dose per area of pancreatic islets and normalized by animal body weight (\%ID $\left.\times 10^{6} / \mathrm{mm}^{2} / \mathrm{kg}\right)$. The level of apoptotic cells in pancreatic islets was expressed as the number of TUNELpositive cells per area of pancreatic islets (cells $/ \mathrm{mm}^{2}$ ). Results: The $99 \mathrm{~m}$ Tc-annexin A5 accumulation level was significantly higher $\left(2.5 \pm 0.7\right.$ vs. $\left.0.7 \pm 0.1 \% \mathrm{ID} \times 10^{6} / \mathrm{mm}^{2} / \mathrm{kg}, P<0.05\right)$ and the number of TUNEL-positive cells was significantly higher $\left(1,170 \pm 535\right.$ vs. $5 \pm 6$ cells $\left./ \mathrm{mm}^{2}, P<0.05\right)$ in the pancreatic islets of the streptozotocin-treated mice than in those of the vehicle-treated mice. The ${ }^{99 \mathrm{~m} T c}$-annexin A5 accumulation level was significantly higher $\left(1.1 \pm 0.4\right.$ vs. $0.5 \pm 0.1 \% \mathrm{ID} \times 10^{6} / \mathrm{mm}^{2} /$ $\mathrm{kg}, P<0.05)$ and the number of TUNEL-positive cells was significantly higher $\left(152 \pm 82\right.$ vs. $4 \pm 9$ cells $\left./ \mathrm{mm}^{2}, P<0.05\right)$ in the pancreatic islets of 16-wk-old NOD mice than in those of 5-wk-old NOD mice. In addition, the level of $99 \mathrm{mTc}$-annexin A5 correlated with the number of TUNEL-positive cells in the pancreatic islets of the streptozotocin-treated mice $(r=0.821, P<$ $0.001)$ and NOD mice $(r=0.721, P<0.001)$. Conclusion: There is significant islet cell apoptosis with ${ }^{99 m}$ Tc-annexin A5 accumulation in the pancreas of both streptozotocin and NOD mice.

Received Dec. 26, 2011; revision accepted May 3, 2012.

For correspondence or reprints contact: Yuji Kuge, Central Institute of Isotope Science, Hokkaido University, Kita 15 Nishi 7, Kita-ku, Sapporo 060-0815, Japan.

E-mail: kuge@ric.hokudai.ac.jp

Published online Aug. 28, 2012.

COPYRIGHT (C) 2012 by the Society of Nuclear Medicine and Molecular Imaging, Inc.
Key Words: type 1 diabetes mellitus; pancreatic beta cells; apoptosis; molecular imaging; $99 \mathrm{mTc}$-annexin A5

J Nucl Med 2012; 53:1585-1591

DOI: 10.2967/jnumed.111.102459

$\mathbf{T}$

ype 1 diabetes mellitus (T1DM) is typically an autoimmune disease resulting from specific destruction of $\beta$-cells in pancreatic islets $(1,2)$. Once a threshold of $\beta$-cell loss is reached, the pancreas is no longer able to secrete a sufficient amount of insulin to maintain glucose homeostasis, resulting in diabetes mellitus. $\beta$-cell apoptosis has been demonstrated in experimental models of T1DM (3-5), suggesting the potential role of apoptosis in the progression of the disease. However, understanding of the relationship of $\beta$-cell apoptosis to the onset of T1DM is limited. In recent years, molecular imaging techniques have been developed to visualize apoptosis. One method uses the intravenous administration of ${ }^{99 \mathrm{~m} T c-a n n e x i n ~ A 5, ~ w h i c h ~ b i n d s ~ w i t h ~ n a n o m o l a r ~ a f f i n i t y ~}$ to phosphatidylserine expressed on the outer leaflet of the cell membrane of cells undergoing apoptosis (6). In this study, we have applied this technique to evaluate apoptosis of $\beta$-cells in the following 2 murine models of T1DM: streptozotocin-treated mice, as a well-established acute model of T1DM $(4,7,8)$, and nonobese diabetic (NOD) mice, as a model of spontaneous T1DM $(2,3)$.

Previously, Medarova et al. were able to detect the apoptosis of $\beta$-cells in the animal models of T1DM in vitro and ex vivo by conjugating a commercially available fluorescent substance, Cy5.5, with annexin A5 (7). However, for the in vivo detection of $\beta$-cell apoptosis, a radionuclide label may be better because of its ability to detect the sites of localization externally. Annexin A5 labeled with a radionuclide such as ${ }^{99 \mathrm{~m}} \mathrm{Tc}$ has been used for the noninvasive imaging of apoptosis in various human diseases, such as myocardial infarction (9), atherosclerosis $(10,11)$, and tumor response to chemotherapy (12-14). To evaluate the feasibility of 


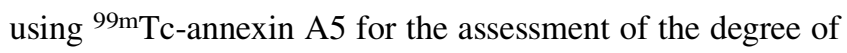
$\beta$-cell apoptosis in the pancreas, we compared the accumulation of ${ }^{99 \mathrm{~m}} \mathrm{Tc}$-annexin A5 with histopathologic changes of $\beta$-cells in the pancreas of both the streptozotocin-treated and the NOD murine models.

\section{MATERIALS AND METHODS}

\section{Preparation of ${ }^{99 m} \mathrm{mc}-A n n e x i n$ A5}

Recombinant human annexin A5 derivatized with hydrazinonicotinamide was kindly donated by the National Cancer Institute (NCI-Frederick Cancer Research and Development Center). Hydrazinonicotinamide-annexin A5 was labeled with ${ }^{99 \mathrm{~m}} \mathrm{Tc}$ using tricine as the coligand as described previously (specific activity, 4.2 $\mathrm{MBq} / \mu \mathrm{g}$ of protein) (15).

\section{Animal Studies}

Animal care and all experimental procedures were performed with the approval of the Animal Care Committee at Hokkaido University. Male BALB/c mice and female NOD mice were obtained from Clea Japan Inc. The mice were kept under a 12-h light cycle with free access to a standard diet and water in a temperaturecontrolled facility at the Laboratory of Animal Experiments at Hokkaido University. In this study, we used 2 animal models of T1DM. The first was a streptozotocin-induced model generated by an intraperitoneal injection of streptozotocin $(120$ or $200 \mathrm{mg} / \mathrm{kg}$ of body weight) in 10-wk-old BALB/c mice $(n=5)$; a vehicle was used for the control $(n=5)(4,7,8)$. Islet cell apoptosis was evaluated $30 \mathrm{~h}$ after the streptozotocin injection. The second was the NOD model of spontaneous T1DM, evaluated in 5-, 9-, 16-, and 20 -wk-old NOD mice ( $n=5-8$ animals per group) $(2,3)$. Blood glucose level was measured by tail snip in the fed state at 10:00 AM daily using Glucocard (Arkray Inc.).

\section{Autoradiographic Studies}

For injection of ${ }^{99 \mathrm{~m} T c-a n n e x i n ~ A 5 ~(18.5 ~ M B q / m o u s e), ~ t h e ~ m i c e ~}$ were anesthetized with light ether and injected intravenously. Six hours after ${ }^{99 \mathrm{~m}} \mathrm{Tc}$-annexin A5 injection, the animals were sacrificed, and the pancreas was harvested under pentobarbital anesthesia $(0.025$ $\mathrm{mg} / \mathrm{kg}$ of body weight, intraperitoneally), frozen, and cut into $10-\mu \mathrm{m}-$ thick sections using a cryomicrotome. To visualize the distribution of 99mTc-annexin A5 in the pancreas, the sections were placed on phosphor imaging plates (Fuji Imaging Plate, BAS-SR 2025; Fuji Photo Film Co., Ltd.) for $15 \mathrm{~h}$ together with the calibrated standards (16). The exposed imaging plates were scanned with a Fuji Bio-Imaging Analyzer (BAS-5000 [Fuji Photo Film Co., Ltd.]; internal resolution, $25 \mu \mathrm{m})$. The autoradiograms were analyzed using image analysis software (Multi Gauge, version 3.0; Fuji Photo Film Co., Ltd.).

\section{Histopathologic Studies}

After the autoradiographic exposure, the same sections were fixed with $4 \%$ paraformaldehyde and underwent immunohistochemical staining of insulin for confirmation of the presence of pancreatic islets. The immunohistochemical staining of insulin was performed using a polyclonal rabbit antiinsulin antibody (H-86; Santa Cruz Biotechnologies) with a Vectastain Elite ABC kit (Vector Laboratories, Inc.). Apoptotic cells were determined by terminal deoxynucleotidyl transferase-mediated dUTP nick-end labeling (TUNEL) staining using a section adjacent to the section that was used for the autoradiographic study (17). The sections were fixed with $4 \%$ paraformaldehyde and stained in accordance with a standard protocol using a commercially available kit (an in situ apoptosis kit; Takara Bio Inc.). The number of TUNEL-positive cells in pancreatic islets was counted under a Biozero BZ-8000 microscope (Keyence Corp.), and the obtained images were analyzed with image analysis software (VH-H1A5, version 2.6; Keyence Corp.) for calculation of TUNEL-positive cell density (cells $/ \mathrm{mm}^{2}$ ).

\section{Coregistration of Images and Evaluation of 99mTc-Annexin A5 Accumulation Level}

As described previously (18), the raw data from the autoradiographic images were digitally scanned using a BAS-5000 device, and the corresponding histopathologic images captured using the Biozero BZ-8000 microscope were transferred to a computer. Autoradiographic images were magnified and analyzed using Multi Gauge image analysis software (version 3.0; Fuji Photo Film Co., Ltd.). Histopathologic images were simultaneously magnified and analyzed using VH-H1A5 image analysis software. Both autoradiographic images and corresponding histopathologic images were magnified and displayed side by side on the same screen. Autoradiographic images were converted into color-coded images, and the positive areas were traced as exposed cross-sections. With an interactive threshold operation available in Multi Gauge, we used the autoradiographic images to manually set threshold values, isolating the structures of cross-sections from the background. After the autoradiographic images and histopathologic figures were aligned, regions of interest were manually drawn on pancreatic islets. The radioactivity in each region of interest was determined as photostimulated luminescence per unit area (PSL $=\mathrm{a} \times$ $\mathrm{D} \times \mathrm{t}$, where $\mathrm{a}$ is a constant, $\mathrm{D}$ is the radioactivity exposed on the imaging plate, and $\mathrm{t}$ is the exposure time). Each count (PSL/mm $\left.\mathrm{mm}^{2}\right)$ from a pancreatic islet was recorded and converted to percentage injected dose per area of the pancreatic islet $\left(\% \mathrm{ID} / \mathrm{mm}^{2}\right)$ using the activity of the standards. The data were normalized by animal body weight $\left(\% \mathrm{ID} / \mathrm{mm}^{2} / \mathrm{kg}\right)$.

\section{Statistical Analyses}

All numeric parameters were expressed as mean $\pm \mathrm{SD}$. To test the significance of differences in body weight and blood glucose level among streptozotocin $(120 \mathrm{mg} / \mathrm{kg})-$, streptozotocin $(200 \mathrm{mg} / \mathrm{kg})-$, and vehicle-treated mice or among NOD mice at different ages, the data were first subjected to a Bartlett test for homogeneity of variance. Because the Bartlett test indicated homogeneity of variance (i.e., Bartlett test value, >0.05), 1-way ANOVA followed by the Bonferroni post hoc test were performed. In addition, to test the significance of differences in ${ }^{99 \mathrm{~m} T c-a n n e x i n}$ A5 accumulation and apoptosis levels among these 3 treated groups of mice or among NOD mice at different ages, the data were first subjected to a Bartlett test for homogeneity of variance. Because this test indicated heterogeneity of variance (i.e., Bartlett's test value, $<0.05$ ), the nonparametric Kruskal-Wallis test followed by the Games-Howell multiple-comparisons test was performed. The correlation between ${ }^{99 \mathrm{~m}} \mathrm{Tc}$-annexin A5 accumulation level and the number of TUNEL-positive cells was assessed with the Spearman correlation coefficient by rank analysis. A 2-tailed $P$ value of less than 0.05 was considered statistically significant.

\section{RESULTS}

\section{Body Weight and Blood Glucose Level}

The body weight and blood glucose level of streptozotocin-treated mice, vehicle-treated mice, and NOD mice at different ages are shown in Table 1. Among streptozotocinand vehicle-treated mice, no significant difference was ob- 
TABLE 1

Body Weights and Blood Glucose Levels in Streptozotocin-Treated Mice and NOD Mice

\begin{tabular}{|c|c|c|}
\hline Mouse group & $\begin{array}{c}\text { Body } \\
\text { weight (g) }\end{array}$ & $\begin{array}{l}\text { Blood glucose } \\
\text { level (mg/dL) }\end{array}$ \\
\hline Vehicle-treated $(n=5)$ & $25.2 \pm 1.0$ & $103 \pm 16$ \\
\hline \multicolumn{3}{|l|}{ Streptozotocin-treated } \\
\hline $120 \mathrm{mg} / \mathrm{kg}(n=5)$ & $23.8 \pm 1.6$ & $124 \pm 37$ \\
\hline 200 mg/kg $(n=5)$ & $25.7 \pm 1.0$ & $90 \pm 30$ \\
\hline \multicolumn{3}{|l|}{ NOD } \\
\hline 5-wk-old $(n=8)$ & $16.6 \pm 1.1$ & $119 \pm 44$ \\
\hline 9-wk-old $(n=6)$ & $20.6 \pm 0.9^{*}$ & $132 \pm 30$ \\
\hline 16-wk-old $(n=8)$ & $24.1 \pm 1.3^{*}, \dagger$ & $119 \pm 14$ \\
\hline 20-wk-old $(n=5)$ & $22.2 \pm 1.3^{\star}, \neq$ & $119 \pm 30$ \\
\hline \multicolumn{3}{|c|}{$\begin{array}{l}{ }^{*} P<0.05 \text { vs. } 5 \text {-wk-old group. } \\
{ }^{\dagger} P<0.05 \text { vs. } 9 \text {-wk-old group. } \\
{ }^{\ddagger} P<0.05 \text { vs. } 16 \text {-wk-old group. } \\
\text { Data represent mean } \pm \text { SD ( } n=5-8 / \text { group }) .\end{array}$} \\
\hline
\end{tabular}

served in body weight or blood glucose level. In the NOD mice, body weight gradually increased with age up to 16 wk and declined at $20 \mathrm{wk}$, whereas no significant difference was observed in blood glucose level among all groups.

\section{Autoradiographic Studies of ${ }^{99 m}$ Tc-Annexin A5}

Figure 1 shows the autoradiograms and corresponding images of immunohistochemical staining of insulin in the pancreas of streptozotocin- and vehicle-treated mice injected with ${ }^{99 \mathrm{~m}} \mathrm{Tc}$-annexin A5. In the pancreas of streptozotocin $(200 \mathrm{mg} / \mathrm{kg})$-treated mice, ${ }^{99 \mathrm{~m}} \mathrm{Tc}$-annexin A5 preferentially accumulated in the regions showing insulin staining (pancreatic islets). In contrast, the accumulation level of ${ }^{99 \mathrm{~m}} \mathrm{Tc}$-annexin A5 in the pancreatic islets of vehicletreated mice was as low as that of the exocrine pancreas.

Figure 2 shows the autoradiograms and corresponding images of immunohistochemical staining of insulin in the pancreas of NOD mice injected with ${ }^{99 \mathrm{~m}} \mathrm{Tc}$-annexin A5. ${ }^{99 m}$ Tc-annexin A5 preferentially accumulated in the pancreatic islets of 16-wk-old NOD mice. In contrast, the accumulation level of ${ }^{99 \mathrm{~m}} \mathrm{Tc}$-annexin A5 in the pancreatic islets of 5-wk-old NOD mice was as low as that of the exocrine pancreas.

\section{TUNEL Staining of Pancreatic Islets}

Figure 3 shows the results of TUNEL staining in the pancreas of streptozotocin-treated mice and NOD mice injected with ${ }^{99 \mathrm{~m}} \mathrm{Tc}$-annexin A5. The number of TUNEL-
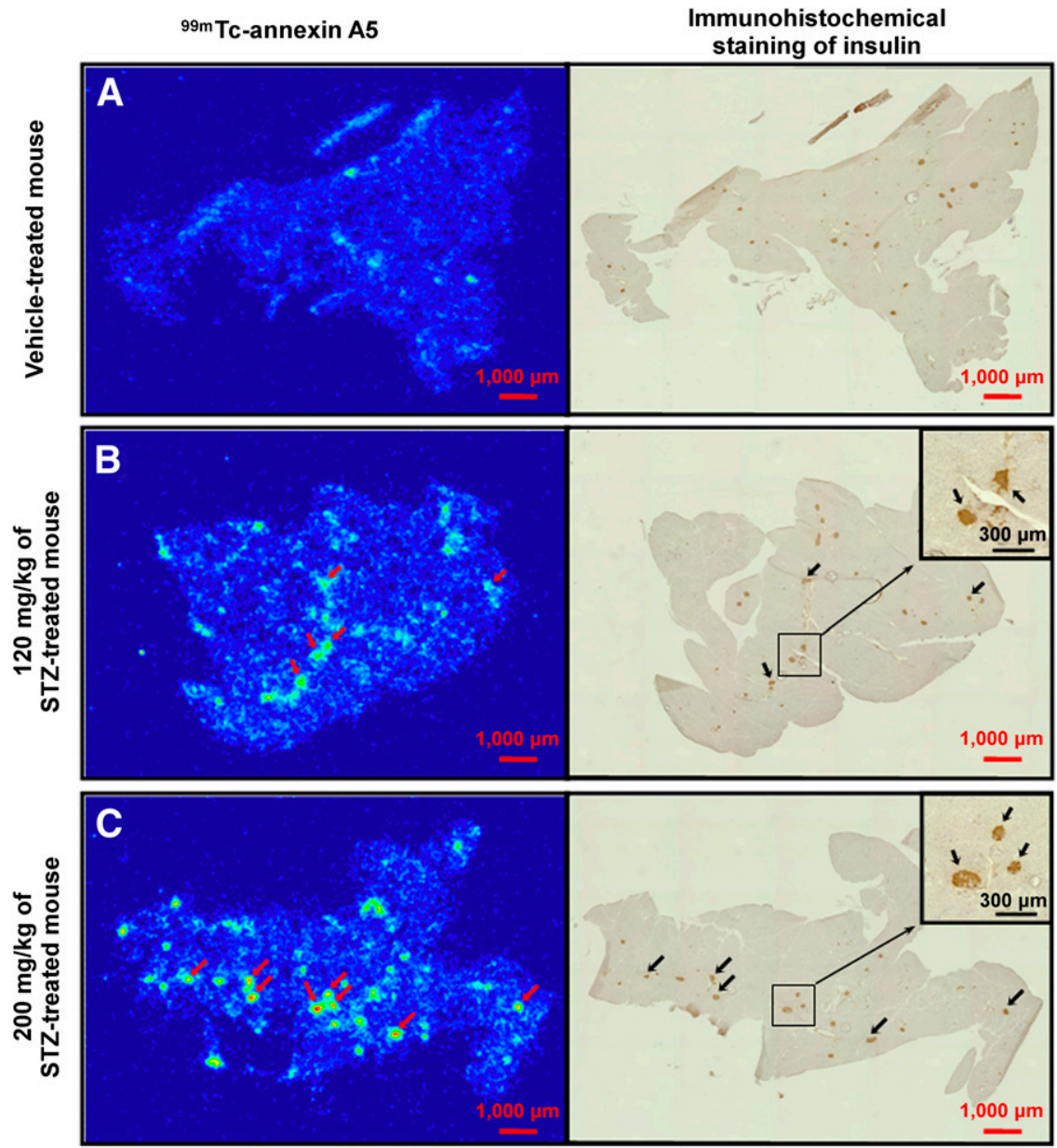

Low
High
FIGURE 1. Autoradiograms and corresponding immunohistochemical staining of insulin in pancreas of mouse treated with vehicle (A), mouse treated with $120 \mathrm{mg} / \mathrm{kg}$ of streptozotocin $(B)$, and mouse treated with $200 \mathrm{mg} / \mathrm{kg}$ of streptozotocin (C) and injected with ${ }^{99 \mathrm{~m} T c-a n n e x i n ~ A 5}$. Boxes indicate magnified areas shown in insets. Black arrows $=$ pancreatic islets (with positive insulin staining); red arrows = regions with high ${ }^{99 m} \mathrm{Tc}$-annexin A5 accumulation (with concomitant insulin staining). Red scale bars $=1,000 \mu \mathrm{m}$, and black scale bars (inset) $=300 \mu \mathrm{m}$. STZ = streptozotocin. 

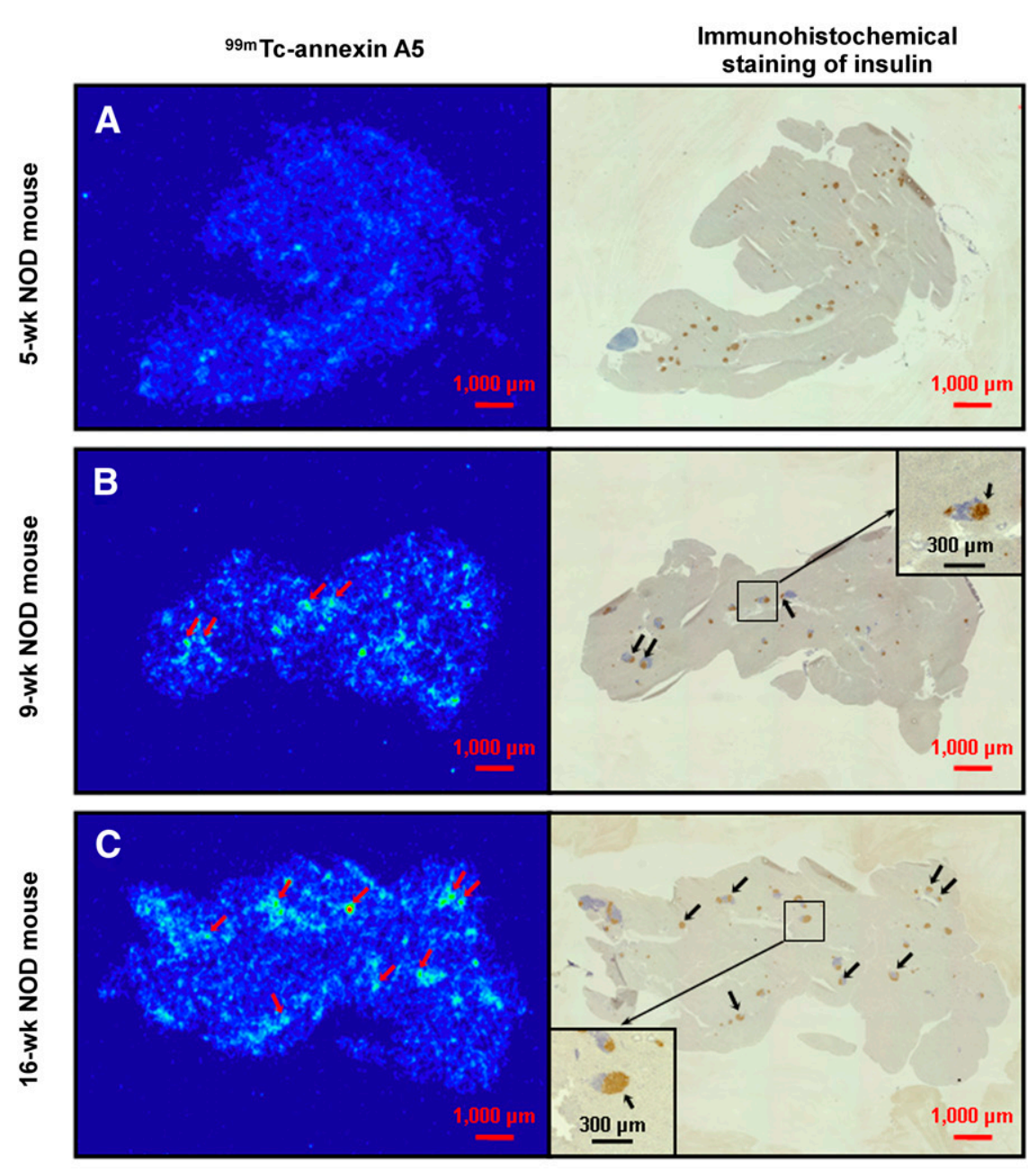

FIGURE 2. Autoradiograms and corresponding immunohistochemical staining of insulin in pancreas of NOD mice at $5(A), 9$ (B), 16 (C), and 20 wk of age (D) injected with 99mTc-annexin A5. Boxes indicate magnified areas shown in insets. Black arrows = pancreatic islets (positive to insulin staining); red arrows $=$ regions with high ${ }^{99 \mathrm{~m} T c-a n n e x i n}$ A5 accumulation (concordant with insulin staining). Red scale bars $=1,000 \mu \mathrm{m}$, and black scale bars (inset) $=300 \mu \mathrm{m}$.

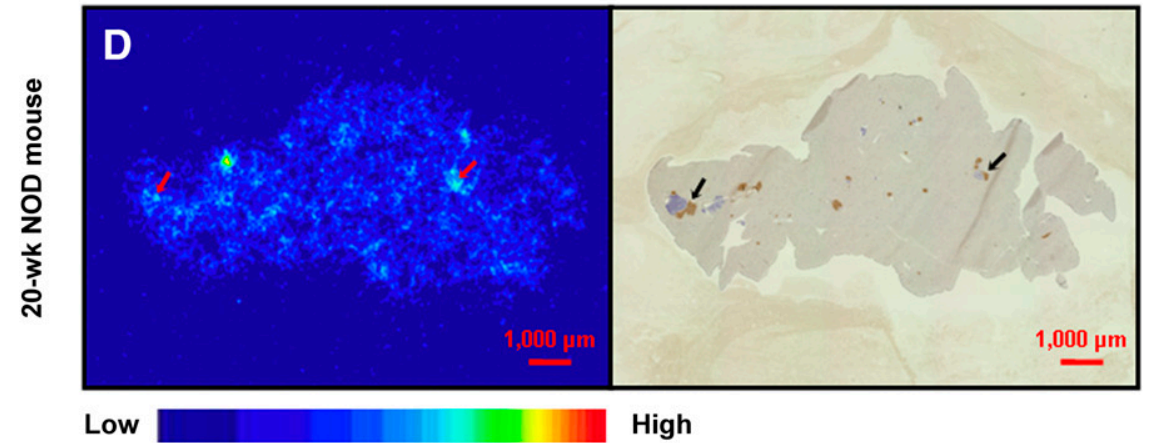

positive cells markedly increased in the pancreatic islets of streptozotocin-treated mice, whereas there were few TUNEL-positive cells in the islets of the vehicle-treated mice. In the pancreatic islets of NOD mice, the number of TUNEL-positive cells increased with age up to $16 \mathrm{wk}$ and declined at $20 \mathrm{wk}$ (Supplemental Fig. 1; supplemental materials are available online only at http://jnm.snmjournals.org).

\section{Quantitative Analysis of ${ }^{99 m}$ Tc-Annexin A5 Accumulation and TUNEL Staining}

${ }^{99 \mathrm{~m}} \mathrm{Tc}$-annexin A5 was nearly 3-fold higher in the pancreatic islets of streptozotocin $(200 \mathrm{mg} / \mathrm{kg})$-treated mice than in those of vehicle-treated mice $(2.5 \pm 0.7$ vs. $0.7 \pm$ $0.1 \% \mathrm{ID} \times 10^{6} / \mathrm{mm}^{2} / \mathrm{kg}, P<0.05$ ) (Fig. 4A). Moreover, ${ }^{99 \mathrm{~m} T c-a n n e x i n ~ A 5 ~ w a s ~ n e a r l y ~ 2-f o l d ~ h i g h e r ~ i n ~ t h e ~ p a n c r e-~}$ atic islets of 16-wk-old NOD mice than in those of 5-wkold NOD mice $\left(1.1 \pm 0.4\right.$ vs. $0.5 \pm 0.1 \% \mathrm{ID} \times 10^{6} / \mathrm{mm}^{2} / \mathrm{kg}$, $P<0.05$ ) (Fig. 4B).

The number of TUNEL-positive cells in the pancreatic islets was significantly higher in streptozotocin $(200 \mathrm{mg} / \mathrm{kg})$ treated mice $\left(1,170 \pm 535 \mathrm{cells} / \mathrm{mm}^{2}\right)$ than in vehicle-treated mice $\left(5 \pm 6\right.$ cells $\left./ \mathrm{mm}^{2}, P<0.05\right)$ (Fig. $\left.4 \mathrm{C}\right)$. In the pancreatic islets of NOD mice, the number of TUNEL-positive cells was significantly higher in mice at $16 \mathrm{wk}$ than in mice 


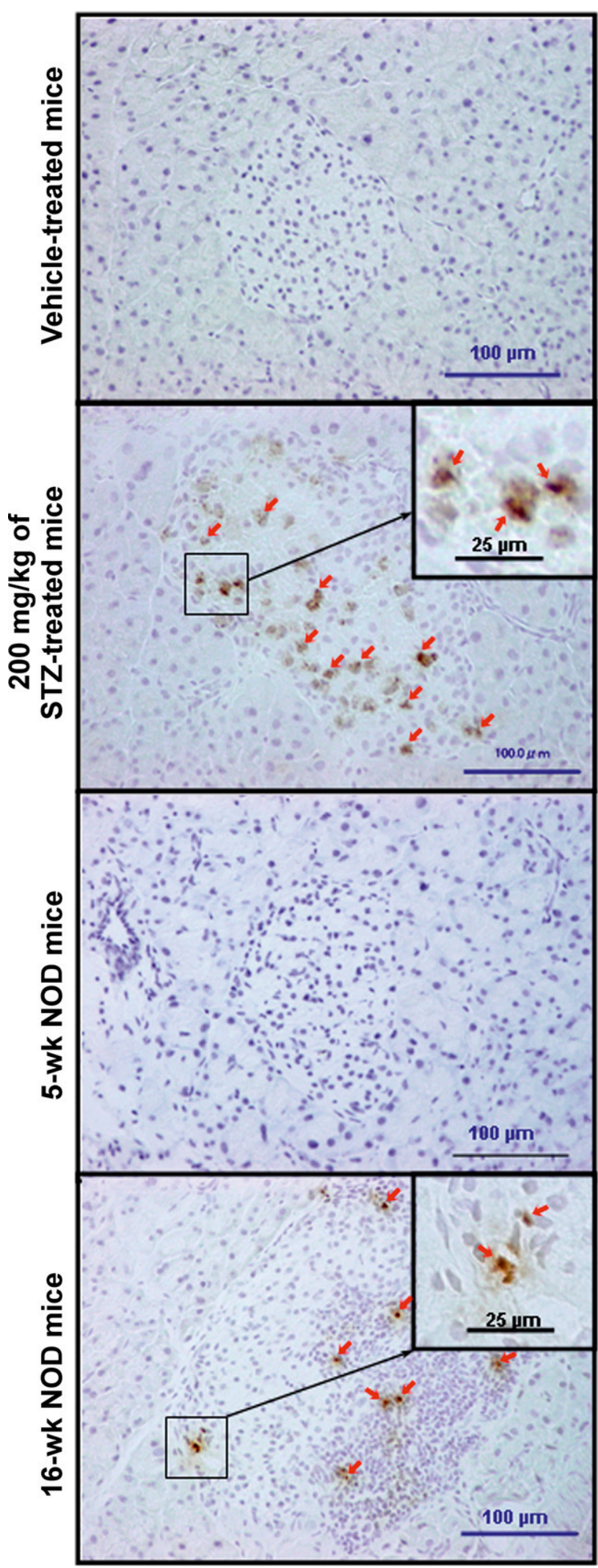

FIGURE 3. TUNEL staining in pancreas of streptozotocin-treated mice and NOD mice injected with ${ }^{99 m}$ Tc-annexin A5. Arrows show TUNEL-positive cells. Boxes indicate magnified areas shown in insets. Blue scale bars $=100 \mu \mathrm{m}$, and black scale bars in inset $=$ $25 \mu \mathrm{m} . \mathrm{STZ}=$ streptozotocin. at 5 wk $\left(152 \pm 82\right.$ vs. $4 \pm 9$ cells $\left./ \mathrm{mm}^{2}, P<0.05\right)$ (Fig. 4D), consistent with the results of ${ }^{99 \mathrm{~m}} \mathrm{Tc}$-annexin A5 accumulation.

The accumulation level of ${ }^{99 \mathrm{~m}} \mathrm{Tc}$-annexin A5 correlated with the number of TUNEL-positive cells in the pancreatic islets of streptozotocin- and vehicle-treated mice $(r=$ 0.821; $P<0.001$ ) (Fig. 5A). In the pancreatic islets of NOD mice, the accumulation level of ${ }^{99 \mathrm{~m}} \mathrm{Tc}$-annexin A5 also positively correlated with the number of TUNEL-positive cells $(r=0.721 ; P<0.001)$ (Fig. 5B).

\section{DISCUSSION}

In this study, we demonstrate apoptosis of insulinproducing pancreatic islet cells in 2 experimental models of T1DM. The relation of the accumulation level of ${ }^{99 \mathrm{~m}} \mathrm{Tc}-$ annexin A5 and the number of TUNEL-positive cells in the pancreas of the streptozotocin-treated mice and NOD mice can be summarized as follows. First, a significantly higher ${ }^{99 \mathrm{~m}} \mathrm{Tc}$-annexin A5 accumulation level was observed in apoptotic $\beta$-cells than in other types of pancreatic cells. Then, regional ${ }^{99 \mathrm{~m} T c-a n n e x i n ~ A 5}$ accumulation level correlated significantly with the number of TUNEL-positive cells in the acute model mice after streptozotocin treatment and in the spontaneous NOD model. In 5-wk-old NOD mice, there was neither localization of ${ }^{99 \mathrm{~m}} \mathrm{Tc}$-annexin A5 nor histologic evidence of apoptosis. In 16-wk-old animals, there was localization of ${ }^{99 \mathrm{~m}} \mathrm{Tc}$-annexin A5 and histologic evidence of apoptosis. These changes occurred without a significant increase in blood glucose level (e.g., before the onset of T1DM).

Medarova et al. used annexin A5 conjugated to the fluorescence marker Cy 5.5 to detect apoptotic $\beta$-cells in streptozotocin-treated and NOD mice of different ages (7). The accumulation level of fluorescence-labeled annexin A5 in apoptotic $\beta$-cells was supported by TUNEL staining. In the current study, we correlated autoradiography of radiolabeled annexin with TUNEL staining in our animal models. Compared with the optical imaging, nuclear imaging offers the advantage of good tissue penetration of $\gamma$-rays. Although the current study used autoradiography to validate the tissue localization of annexin A5, the potential to use this tracer in vivo with external imaging may be helpful to test various therapies to reduce the $\beta$-cell apoptosis that results in T1DM.

A limitation of our study is the lack of in vivo planar or SPECT images of the mice. Noninvasive imaging was not conducted in this study because the mouse pancreas is irregularly shaped and small, making it difficult to identify without high-resolution and high-sensitivity small-animal SPECT equipment. It may be technically feasible to noninvasively image the pancreas using ${ }^{99 \mathrm{~m}} \mathrm{Tc}$-annexin A5 SPECT with contemporaneous CT because the human pancreas is large. It should be noted, however, that the limited spatial resolution of SPECT cannot resolve small pancreatic islets $(100-300 \mu \mathrm{m})$ containing $\beta$-cells that are scattered in the 


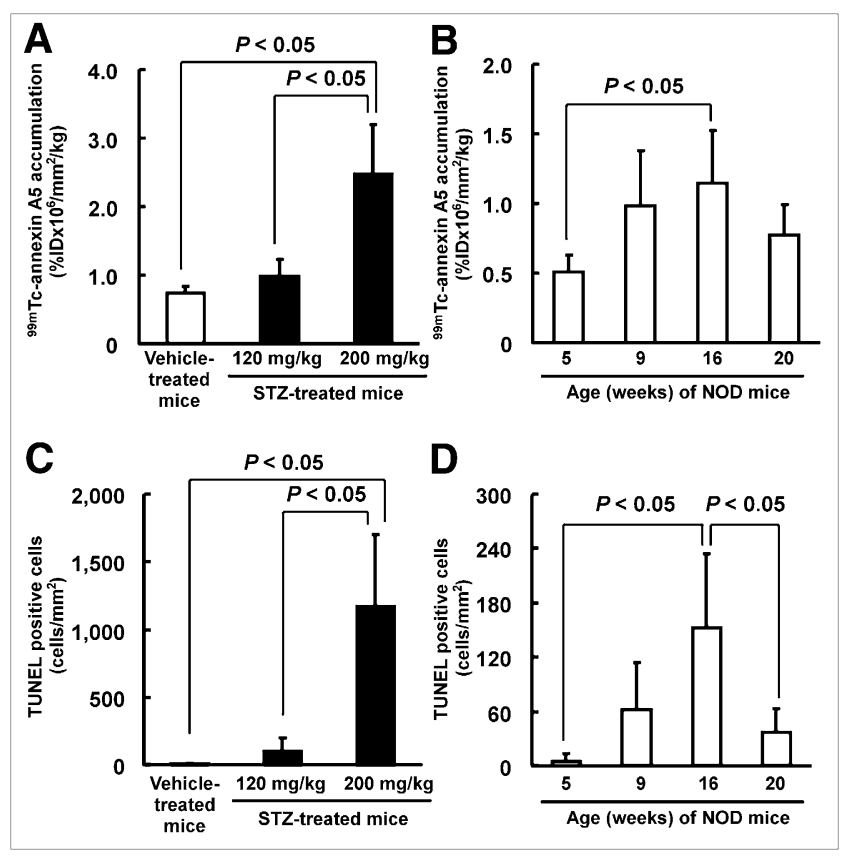

FIGURE 4. ${ }^{99 m}$ Tc-annexin $A 5$ accumulation level and number of TUNEL-positive cells in pancreatic islets of streptozotocintreated mice and NOD mice injected with 99mTc-annexin A5. 99mTc-annexin A5 accumulation levels in pancreatic islets of streptozotocin-treated mice $(A)$ and NOD mice $(B)$ injected with 99mTc-annexin A5 and number of TUNEL-positive cells in pancreatic islets of streptozotocin-treated mice (C) and NOD mice (D) injected with $99 \mathrm{mTc}$-annexin A5 are shown. Data represent mean $\pm \mathrm{SD}$ ( $n=5-8$ /group). STZ = streptozotocin.

pancreas, suggesting that SPECT can be used only to measure the radioactivity of ${ }^{99 \mathrm{~m}} \mathrm{Tc}$-annexin A5 averaged over the entire pancreas. Regarding this point, in our preliminary biodistribution study using the ex vivo counting method in streptozotocin-treated mice, the average radioactivity of ${ }^{99 m}$ Tc-annexin A5 in the entire pancreas was also significantly higher in streptozotocin-treated mice than in vehicletreated mice (Supplemental Fig. 2). In SPECT, however, this average radioactivity also suffers from the partial-volume effects and the scatter from surrounding tissues, although the

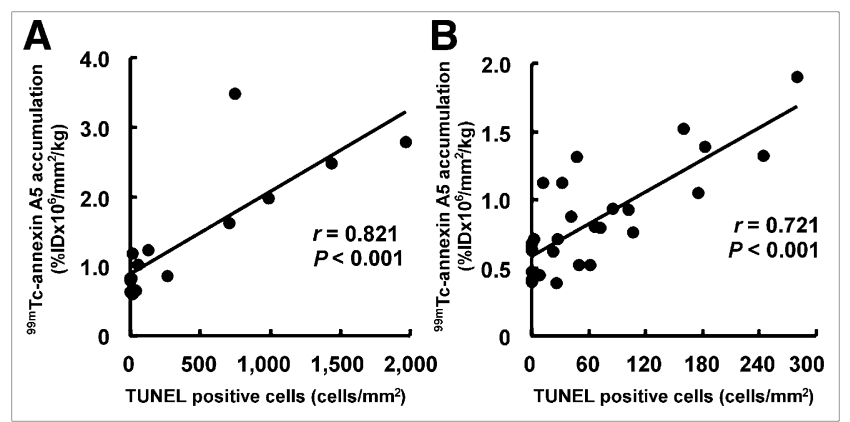

FIGURE 5. Correlations between ${ }^{99 m} \mathrm{Tc}$-annexin A5 accumulation levels and number of TUNEL-positive cells in pancreatic islets of streptozotocin-treated mice $(A)$ and NOD mice (B) injected with 99mTc-annexin A5. Data represent mean \pm SD ( $n=5$-8/group). human pancreas is relatively large in volume (average, 80 $\mathrm{cm}^{3}$ ) (19). The signal intensity is important for successful imaging and signal quantification (20), and that obtained in our study was relatively low. With respect to the signal intensity, PET is more advantageous than SPECT. The development of PET tracers for apoptosis with high affinity and signal intensity might be an alternative approach. The feasibility of noninvasive imaging of the pancreas using ${ }^{99 \mathrm{~m}} \mathrm{Tc}-$ annexin A5 SPECT should be confirmed in future studies.

Regarding nuclear imaging in $\mathrm{DM},{ }^{11} \mathrm{C}$-labeled dihydrotetrabenazine was also reported as a potential tracer of viable $\beta$-cells for the assessment of pancreatic $\beta$-cell mass $(21,22)$. Dihydrotetrabenazine binds specifically to vesicular monoamine transporter type 2, which is expressed at the vesicles that contain insulin and dopamine in pancreatic $\beta$-cells but is absent in the exocrine tissues of the pancreas and many other abdominal tissues $(23,24) .{ }^{11} \mathrm{C}$-dihydrotetrabenazine PET can clearly visualize the pancreas in control rats and healthy subjects. However, results of a study on the feasibility of ${ }^{11} \mathrm{C}$-dihydrotetrabenazine PET quantification of pancreatic vesicular monoamine transporter type 2 binding in healthy subjects and patients with long-standing T1DM showed that the functional vesicular monoamine transporter type 2 binding capacity appears to overestimate $\beta$-cell mass in view of the known near-complete depletion of $\beta$-cell mass in patients with long-standing T1DM (25). Instead of imaging $\beta$-cell mass, we explored the possibility of imaging $\beta$-cell apoptosis. As DM progresses, the increase in the level of $\beta$-cell apoptosis occurs in parallel with the decrease in $\beta$-cell mass. With respect to monitoring therapy, apoptosis tracers would be useful in monitoring therapy that targets the prevention of $\beta$-cell apoptosis in T1DM, and tracers of viable $\beta$-cells would be useful in monitoring therapy that targets the promotion of neogenesis and regeneration of $\beta$-cells and islet transplant in T1DM $(21,26)$. The use of both ${ }^{99 \mathrm{~m}} \mathrm{Tc}$-annexin A5 SPECT/CT and ${ }^{11} \mathrm{C}$-dihydrotetrabenazine PET/CT should enhance the armamentarium to study T1DM.

\section{CONCLUSION}

In the present study, we demonstrated that regional $99 \mathrm{~m} \mathrm{Tc}-$ annexin A5 accumulation level significantly correlated with the number of TUNEL-positive cells in both the acute model and the spontaneous model of T1DM. ${ }^{99} \mathrm{~m}$ Tc-annexin A5 may be useful for diagnosis and possibly for response assessment of individual patients with T1DM to therapy.

\section{DISCLOSURE STATEMENT}

The costs of publication of this article were defrayed in part by the payment of page charges. Therefore, and solely to indicate this fact, this article is hereby marked "advertisement" in accordance with 18 USC section 1734.

\section{ACKNOWLEDGMENTS}

We thank the staff of the Central Institute of Isotope Science and Department of Nuclear Medicine, Hokkaido 
University, for supporting this work and NCI-Frederick Cancer Research and Development Center for providing annexin A5. This study was performed through the Special Coordination Funds for Promoting Science and Technology of the Ministry of Education, Culture, Sports, Science and Technology, the Japanese government, and supported by Shionogi \& Co., Ltd. No other potential conflict of interest relevant to this article was reported.

\section{REFERENCES}

1. Tisch R, McDevitt H. Insulin-dependent diabetes mellitus. Cell. 1996;85:291-297.

2. Thomas HE, Kay TW. Beta cell destruction in the development of autoimmune diabetes in the non-obese diabetic (NOD) mouse. Diabetes Metab Res Rev. 2000;16:251-261.

3. O'Brien BA, Harmon BV, Cameron DP, Allan DJ. Apoptosis is the mode of betacell death responsible for the development of IDDM in the nonobese diabetic (NOD) mouse. Diabetes. 1997;46:750-757.

4. O'Brien BA, Harmon B, Cameron D, Allan D. Beta-cell apoptosis is responsible for the development of IDDM in the multiple low-dose streptozotocin model. J Pathol. 1996;178:176-181.

5. Cnop M, Welsh N, Jonas JC, et al. Mechanisms of pancreatic beta-cell death in type 1 and type 2 diabetes: many differences, few similarities. Diabetes. 2005;54:S97-S107.

6. Thiagarajan P, Tait JF. Binding of annexin A5/placental anticoagulant protein I to platelets: evidence for phosphatidylserine exposure in the procoagulant response of activated platelets. J Biol Chem. 1990;265:17420-17423.

7. Medarova Z, Bonner-Weir S, Lipes M, Moore A. Imaging beta-cell death with a near-infrared probe. Diabetes. 2005;54:1780-1788.

8. Hayashi K, Kojima R, Ito M. Strain differences in the diabetogenic activity of streptozotocin in mice. Biol Pharm Bull. 2006;29:1110-1119.

9. Narula J, Hofstra L. Imaging myocardial necrosis and apoptosis. In: Dilsizian V, Narula J, eds. Atlas of Nuclear Cardiology. Philadelphia, PA: Current Medicine; 2003:197-216.

10. Ishino S, Kuge Y, Takai N, et al. ${ }^{99 \mathrm{~m}} \mathrm{Tc}$-annexin A5 for noninvasive characterization of atherosclerotic lesions: imaging and histological studies in myocardial infarction-prone Watanabe heritable hyperlipidemic rabbits. Eur J Nucl Med Mol Imaging. 2007;34:889-899.
11. Zhao Y, Kuge Y, Zhao S, et al. Comparison of ${ }^{99 m}$ Tc-annexin A5 with ${ }^{18}$ F-FDG for detection of atherosclerosis in ApoE-/- mice. Eur J Nucl Med Mol Imaging. 2007;34:1747-1755.

12. Blankenberg FG, Strauss HW. Nuclear medicine applications in molecular imaging. J Magn Reson Imaging. 2002;16:352-361.

13. Belhocine T, Steinmetz N, Green A, Rigo P. In vivo imaging of chemotherapyinduced apoptosis in human cancers. Ann N Y Acad Sci. 2003;1010:525-529.

14. Mochizuki T, Kuge Y, Zhao S, et al. Detection of apoptotic tumor response in vivo after a single dose of chemotherapy with ${ }^{99 \mathrm{~m}} \mathrm{Tc}$-annexin V. J Nucl Med. 2003;44:92-97.

15. Blankenberg FG, Katsikis PD, Tait JF, et al. In vivo detection and imaging of phosphatidylserine expression during programmed cell death. Proc Natl Acad Sci USA. 1998;95:6349-6354.

16. Brown RS, Leung JY, Fisher SJ, et al. Intratumoral distribution of tritiated fluorodeoxyglucose in breast carcinoma. I. Are inflammatory cells important? J Nucl Med. 1995;36:1854-1861.

17. Piqueras B, Autran B, Debre P, Gorochov G. Detection of apoptosis at the singlecell level by direct incorporation of fluorescein-dUTP in DNA strand breaks. Biotechniques. 1996;20:634-640.

18. Zhao Y, Zhao S, Kuge Y, et al. Localization of deoxyglucose and annexin A5 in experimental atheroma correlates with macrophage infiltration but not lipid deposition in the lesion. Mol Imaging Biol. 2011;13:712-720.

19. Kin T, Murdoch TB, Shapiro AM, Lakey JR. Estimation of pancreas weight from donor variables. Cell Transplant. 2006;15:181-185.

20. Kwee TC, Basu S, Saboury B, Torigian DA, Naji A, Alavi A. Beta-cell imaging: opportunities and limitations. J Nucl Med. 2011;52:493.

21. Souza F, Freeby M, Hultman K, et al. Current progress in non-invasive imaging of beta cell mass of the endocrine pancreas. Curr Med Chem. 2006;13:2761-2773.

22. Harris PE, Ferrara C, Barba P, Polito T, Freeby M, Maffei A. VMAT2 gene expression and function as it applies to imaging beta-cell mass. $\mathrm{J}$ Mol Med (Berl). 2008;86:5-16.

23. Maffei A, Liu Z, Witkowski P, et al. Identification of tissue-restricted transcripts in human islets. Endocrinology. 2004;145:4513-4521.

24. Anlauf M, Eissele R, Schäfer MK, et al. Expression of the two isoforms of the vesicular monoamine transporter (VMAT1 and VMAT2) in the endocrine pancreas and pancreatic endocrine tumors. J Histochem Cytochem. 2003;51:1027-1040.

25. Goland R, Freeby M, Parsey R, et al. ${ }^{11} \mathrm{C}$-dihydrotetrabenazine PET of the pancreas in subjects with long-standing type 1 diabetes and in healthy controls. J Nucl Med. 2009;50:382-389.

26. Evgenov NV, Medarova Z, Dai G, Bonner-Weir S, Moore A. In vivo imaging of islet transplantation. Nat Med. 2006;12:144-148. 